Introduction: Previous studies showed that high and low body mass index (BMI) was associated with worse prognosis in metastatic CRC (mCRC). Whether $\mathrm{BMI}$ is a prognostic or predictive factor in $\mathrm{mCRC}$ is unclear. We aimed to assess efficacy outcomes according to BMI in patient with metastatic colorectal cancer treated with bevacizumab plus FOLFOX chemotherapy regimen in second-line treatment. Material and methods: The analysis of 237 patients with metastatic colorectal cancer treated with bevacizumab plus FOLFOX in the second line (treated from January 2014 to August 2018) in 4 reference oncological centers in Poland.

Results: The median age of the patients was 65 years (range 34-82). The median overall survival (OS) and progression-free survival (PFS) of the al 237 patient was 14.6 and 8.8 months, respectively. Comparison of obese patient $\left(\mathrm{BMI}>30 \mathrm{~kg} / \mathrm{m}^{2}\right)$ vs. overweight patients (BMI $\geq 25$ to $<30 \mathrm{~kg} / \mathrm{m}^{2}$ ) vs. normal BMI range patients revealed a significant improvement of median OS (17.5 vs. 14.3 vs. 13.1 months, $p=0.01)$ and median PFS (9.4 vs. 9.1 vs. 7.3 months, $p=0.03$ ). The Cox hazard model showed that the BMI class is an important risk factor. However the Cox model also showed that the significance of the BMI class applies only to patients with $\mathrm{BMI}<25 \mathrm{~kg} / \mathrm{m}^{2}$. This rule applies to both OS and PFS. The regression analysis also confirmed that there is a statistically significant relationship between the length of $\mathrm{OS}$ and PFS and the BMI value. Higher BMI was associated with a better prognosis. There were no differences in responses to treatment bevacizum$a b$ and FOLFOX chemotherapy and number adverse events according to BMI values.

Conclusions: Patients with $\mathrm{mCRC}$ treated with chemotherapy with bevacizumab in second-line treatment with higher BMI compared with normal weight patients have better prognosis in terms of PFS and OS. In this group, we found no evidence of changes in safety profile depending on BMI. Nevertheless, further large randomized studies are needed to assess the body weight on the effectiveness of chemotherapy in combination with bevacizumab.

Key words: metastatic colorectal cancer, obesity, bevacizumab, body mass index, time to progression.

Contemp Oncol (Pozn) 2020; 24 (1): 34-41 DOI: https://doi.org/10.5114/wo.2020.94728

\section{Overweight is associated with better prognosis in metastatic colorectal cancer patients treated with bevacizumab plus FOLFOX chemotherapy}

\author{
Bożena Cybulska-Stopa ${ }^{1}$, Iwona Ługowska², Rafał Wiśniowski ${ }^{3}$, \\ Małgorzata Domagała-Haduch ${ }^{1}$, Marcin Rajczykowski ${ }^{4}$, Karolina Piejko $^{1}$, \\ Ilona Bar-Letkiewicz ${ }^{5}$, Rafał Suwiński ${ }^{4}$, Krzysztof Regulski ${ }^{6}$, \\ Jacek Mackiewicz ${ }^{5,7,8}$
}

${ }^{1}$ Clinical Oncology Clinic, Maria Sklodowska-Curie National Research Institute of Oncology, Cracow Branch, Crakow, Poland

${ }^{2}$ Department of Soft Tissue/Bone Sarcoma and Melanoma, Maria Sklodowska-Curie National Research Institute of Oncology, Warsaw, Poland

${ }^{3}$ Clinical Oncology Department, Beskid Oncology Center, Bielsko-Biała, Poland ${ }^{4} 2^{\text {nd }}$ Department of Radiotherapy and Chemotherapy, Maria Sklodowska-Curie National Research Institute of Oncology, Gliwice Branch, Gliwice, Poland DDepartment of Diagnostics and Cancer Immunology, Greater Poland Cancer Centre, Poznan, Poland

${ }^{6}$ Department of Applied Computer Science and Modelling, AGH University of Science and Technology, Cracow, Poland

'Department of Medical and Experimental Oncology, Heliodor Świecicki University Hospital, Poznan University of Medical Sciences, Poznan, Poland

${ }^{8}$ Department of Biology and Environmental Studies, Poznan University of Medical Sciences, Poznan, Poland

\section{Introduction}

Obesity is a known factor associated with death [1] and is a well-known carcinogenic factor for colorectal cancer [2-4]. Obesity can cause production of vascular endothelial growth factor (VEGF), angiopoietin-2, and other growth factors that induce tumor growth $[5,6]$. Cancer progression and carcinogenesis can be modified by chronic inflammation, insulin, leptin, endogenous sex steroids, plasminogen activator inhibitor-1, and adiponectin $[7,8]$.

However, there is evidence that there is no relationship between obesity and the risk of death in some patients. In addition, there are studies indicating a lower risk of death in patients with certain cancers [9]. This phenomenon is called "obesity paradox". The beneficial effects of overweight and obesity in some group of patients are suggested [10-12]

$\mathrm{BMI}$ is an index assessing body weight and informing about normal or abnormal body weight (underweight, overweight, obesity). Although new tools for assessing overweight and obesity are being studied, for example visceral fat area (VFA) and subcutaneous fat area (SFA), measured with computed tomography, waist circumference [9]. BMI is still a basic and simpler tool for determining normal and abnormal body weight. For this reason, $\mathrm{BMI}$ is the most common parameter used in analyses related to the assessment of the effect of body weight on the treatment [9]. Whether body mass index (BMI) is a prognostic or predictive factor in $\mathrm{mCRC}$ is unclear. Also, the relationship between obesity and anti-angiogenic treatment has not yet been clearly defined.

Bevacizumab is a humanized monoclonal antibody (mAb) against VEGF and in combination with chemotherapy/immunotherapy is approved for the treatment of advanced colorectal, renal cancer and non-small cell lung can- 
cer, as well as metastatic breast cancer [13]. Its mechanism of action is to selectively bind circulating VEGF and thus to inhibit the interaction of VEGF with its cells receptors. By lowering interstitial pressure in tissues and increasing vascular permeability, the delivery of chemotherapeutic agents into tumor is increase and it leads to tumor endothelial cells apoptosis. On the other hand bevacizumab also causes a reduction in microvascular growth of tumor blood vessels and angiogenesis [13].

Previous studies showed that BMI was associated with prognosis in early-stage CRC, specially low BMI was associated with worse prognosis in metastatic CRC (mCRC) [4]. Other studies have shown that overweight and obesity may be a negative prognostic factor in patients with $\mathrm{mCRC}$ and bevacizumab may be less effective in obese MCRC patients [14]. VEGF is a key angiogenic factor that stimulates growth of tumours [15]. Obese people have higher levels of circulating VEGF and for this reason, anti-VEGF therapy can be less effective. There is no consensus about the impact of obesity in bevacizumab-treated mCRC patients. We need more research to understand the relationship between bevacizumab and obesity.

Therefore, the aim of our study was assessment of the associations between BMI and clinical outcomes in patients administered bevacizumab-based treatments for metastatic CRC in the second line treatment.

\section{Material and methods}

In this retrospective study, 237 patients with metastatic colorectal cancer treated from January 2014 to August 2018 in 4 reference oncological centers in Poland were included in the analysis. All patients had histopathologically confirmed colon cancer and received bevacizumab with FOLFOX chemotherapy (oxaliplatin, 5-Fluorouracil, leucovorin) as second-line treatment. In the first-line treatment, all patients received irinotecan based chemotherapy (XELIRI or FOLFIRI). Patients who progressed after second line systemic therapy received panitumumab or cetuximab in third line only when mutation in KRAS gene was not present. Presented regimens were standard treatment in Poland in those years.

Complete data were collected on patients such as age, gender, type and location of primary tumor, K-RAS mutation, type of systemic treatment due to $\mathrm{mCRC}$ and detailed data on patients at the time of qualification for systemic treatment of the second line, such as fitness status, weight and height, location of metastases, serum CEA (carcinoembryonic antigen) level. All patients had a performance status of 0 or 1 according to ECOG (Eastern Cooperative Oncology Group) $[16,17]$. In all patients, imaging was performed every 12 weeks with bevacizum$a b$ and FOLOFOX chemotherapy to assess effectiveness of the treatment. Assessments was made using RECIST (Response Criteria in Solid Tumors) version 1.1 [18].

In all patients the BMI index was calculated before the start of bevacizumab treatment with FOLFOX chemotherapy. The BMI index is numerous as the weight in kilograms by the height in meters squared (weight/height ${ }^{2}$ ). BMI categories were determined according to WHO criteria (BMI classification World Health Organisation. http://apps.who. int/bmi). Categories BMI: obese BMI $\geq 30 \mathrm{~kg} / \mathrm{m}^{2}$, overweight $\mathrm{BMI} \geq 25-<30 \mathrm{~kg} / \mathrm{m}^{2}$, normal weight $(\mathrm{BMI} \geq 18.5$ $-<25 \mathrm{~kg} / \mathrm{m}^{2}$ and underweight $<18,5 \mathrm{~kg} / \mathrm{m}^{2}$.

\section{Statistical analysis}

All statistical analyses were performed using STATISTICA 12. The analysis of variance (ANOVA) was used to determining the significance of impact on quantitative variables, while for qualitative variables chi-squared tests were used to compare probability distributions of patient from different BMI groups. The statistical significance of differences in means for quantitative variables was tested by Student's $t$ test at the level of significance $p=0.05$. The regression analysis (Pearson's linear correlation coefficient) were used in order to analyzed the relationship between the length of OS and PFS and the BMI value. Test F (Fisher's exact test) was used to investigate deeper for relationships among variables in multivariate model. Test $F$ allows assessing the importance of the predictors involved in the model. The test value takes into account the sum of squared residuals (error) of the model using a given parameter and the reduced model - without it. In this way, we can determine how much a given predictor improves the predictive quality of the model. The objective of the study was to assess the correlation of BMI value and progression-free survival (PFS) and overall survival (OS) of $\mathrm{mCRC}$ treated in second line with bevacizumab with chemotherapy. OS time was calculated from the date of the start of II line treatment to the date of the most recent follow-up or death. PFS time was calculated from the date of the start of II line treatment to the date of the most recent follow-up, or progression or death due to the disease. Radiological response was assessed according to RECIST in third month of treatment The differences were considered statistically significant if the $p$-values were $<0.05$. Survival analyzes including truncated observations were made using Kaplan-Maier models and the Cox hazard model. Both models take into account (in contrast to the previously mentioned methods) the fact that some patients during the analysis are complete observations (fatal), and the remaining records concern living patients whose OS and PFS will be prolonged.

The results of analyzes performed with different methods may differ (and differ) in the aspect of $p$ value due to the different power of statistical tests used in these methods. The juxtaposition of various results was intended to emphasize that, regardless of the method used, the BMI factor is important in predicting the effectiveness of therapy, and the differences may result from the method of discretization (division point and number of groups) or the number of observations in individual classes.

\section{Results}

The median age of the patients was 65 years (range 3482). The cohort included $46 \%$ of females and $54 \%$ males. The proportion of female patients was higher in the nonobese group (34 vs. 21\%, p < 0.001). Other factors like age, location of the primary tumor, the type of treatment in the 
Table 1. Correlation between body mass index level and clinical characteristics of metastatic colorectal patients treated with bevacizumab plus FOLFOX chemotherapy

\begin{tabular}{|c|c|c|c|c|c|c|}
\hline \multirow[t]{2}{*}{ Characteristic } & & \multicolumn{5}{|c|}{ BMI category } \\
\hline & & $\begin{array}{l}<25 \mathrm{~kg} / \mathrm{m}^{2} \\
n=74(31 \%)\end{array}$ & $\begin{array}{l}\geq 25-30 \mathrm{~kg} / \mathrm{m}^{2} \\
n=109(46 \%)\end{array}$ & $\begin{array}{c}\geq 30 \mathrm{~kg} / \mathrm{m}^{2} \\
n=54(23 \%)\end{array}$ & $\begin{array}{l}\text { Total } \\
n=237\end{array}$ & $p$-value \\
\hline Age & $\begin{array}{l}\text { Median, years } \\
\text { (range) }\end{array}$ & $63(34-80)$ & $66(41-82)$ & 65 (43-78) & $65(34-82)$ & 0.115 \\
\hline \multirow[t]{2}{*}{ Sex } & Male & $27(21)$ & $69(54)$ & $32(25)$ & $128(54)$ & 0.001 \\
\hline & Female & $47(43)$ & $40(37)$ & $22(20)$ & $109(46)$ & \\
\hline \multirow[t]{2}{*}{ Location } & Left site & $55(30)$ & $82(45)$ & $45(25)$ & $183(78)$ & 0.529 \\
\hline & Right site & $18(35)$ & $25(48)$ & $9(17)$ & $52(22)$ & \\
\hline \multirow[t]{3}{*}{ I line therapy } & FOLFIRI & $22(30)$ & $31(42)$ & $20(28)$ & $73(33)$ & 0.079 \\
\hline & XELIRI & $49(35)$ & $61(43)$ & $32(22)$ & $142(63)$ & \\
\hline & XELIRI/FOLFIRI & $1(11)$ & $8(89)$ & $0(0)$ & $9(4)$ & \\
\hline \multirow[t]{2}{*}{ CEA } & Normal & $6(20)$ & $19(63)$ & $5(17)$ & $30(16)$ & 0.146 \\
\hline & $>5$ & $53(33)$ & $70(44)$ & $36(23)$ & 159 (84) & \\
\hline \multirow{2}{*}{$\begin{array}{l}\text { Number of } \\
\text { metastatic sites }\end{array}$} & 1 & $30(28)$ & $49(45)$ & $29(27)$ & $108(46)$ & 0.168 \\
\hline & $\geq 2$ & $46(36)$ & $58(45)$ & $25(19)$ & $129(54)$ & \\
\hline \multirow[t]{3}{*}{ KRAS gene status } & Wild-type & $22(30)$ & $29(39)$ & $23(31)$ & $22(31)$ & 0.178 \\
\hline & Mutated & $17(28)$ & $29(48)$ & $15(25)$ & $17(26)$ & \\
\hline & Not available & $35(34)$ & $51(50)$ & $16(16)$ & $35(43)$ & \\
\hline
\end{tabular}

BMI - body mass index, FOLFOX - chemotherapy with oxaliplatin, 5-fluorouracil, leucovorin, FOLFIRI-chemotherapy with irinotecan, 5-fluorouracil, leucovorin, XELIRI - chemotherapy with irinotecan, capecytabine

first line, the level of CEA and the number of locations metastases did not differ depending on the BMI category. Patient characteristics according to BMI are shown in Table 1. Only 3 patients had BMI $<18.5 \mathrm{~kg} / \mathrm{m}^{2}\left(18.0-18.4 \mathrm{~kg} / \mathrm{m}^{2}\right)$, therefore they were included in the BMI group $<25 \mathrm{~kg} / \mathrm{m}^{2}$. The median OS and PFS of the all 237 patients was 14.6 and 8.8 months, respectively. Comparison of obese patient $\left(\mathrm{BMI}>30 \mathrm{~kg} / \mathrm{m}^{2}\right)$ vs. overweight patients (BMI $\geq 25$ to $\left.<30 \mathrm{~kg} / \mathrm{m}^{2}\right)$ vs. normal BMI range patients revealed a significant improvement of median OS (17.5 vs. 14.3 vs. 13.1 months, $p=0.01$ ) (Fig. 1) and median PFS (9.4 vs. 9.1 vs.
7.3 months, $p=0.03$ ) (Fig. 2). There were no differences in the responses to bevacizumab and FOLFOX chemotherapy treatment and number adverse events according to BMI values. Adverse events during treatment were evaluated according to Common Terminology Criteria for Adverse Events (CTCAE) Version 4.0 [19]. The most common serious adverse reactions during treatment were neutropenia (G3/ G4: $35 \%$ patients), polyneuropathy (G2: $10 \%$ and G3: $2 \%$ patients), diarrhea (G3/G4: 12\% patient), proteinuria (G3: 2\% patients), hypertension (G3: 5\% patients) and thromboembolic events (G3: 5 \% patient), intestinal perforation

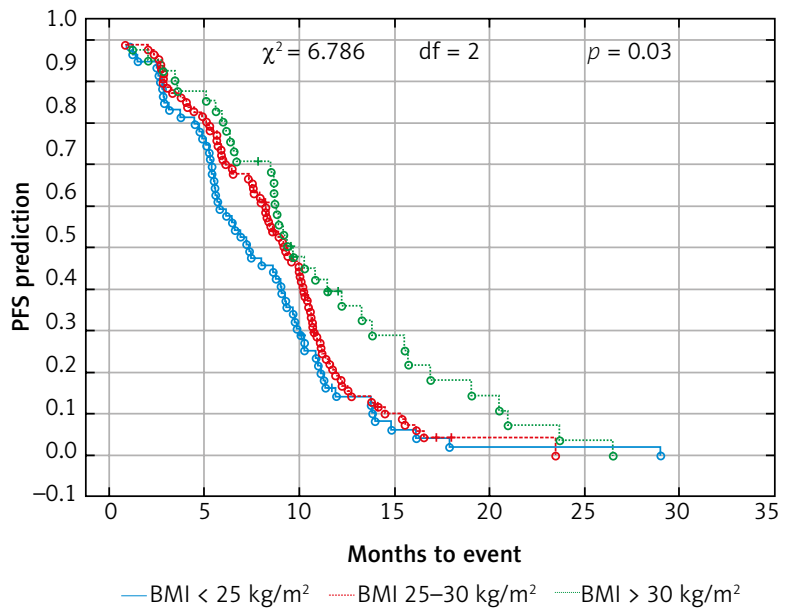

Fig. 1. Probability of Kaplan-Meier's progression-free survival (PFS) curves in patients with BMI (body mass index): $<25 \mathrm{~kg} / \mathrm{m}^{2}, 25-30$ $\mathrm{kg} / \mathrm{m}^{2}$ and $>30 \mathrm{~kg} / \mathrm{m}^{2}$ treated with bevacizumab plus chemotherapy

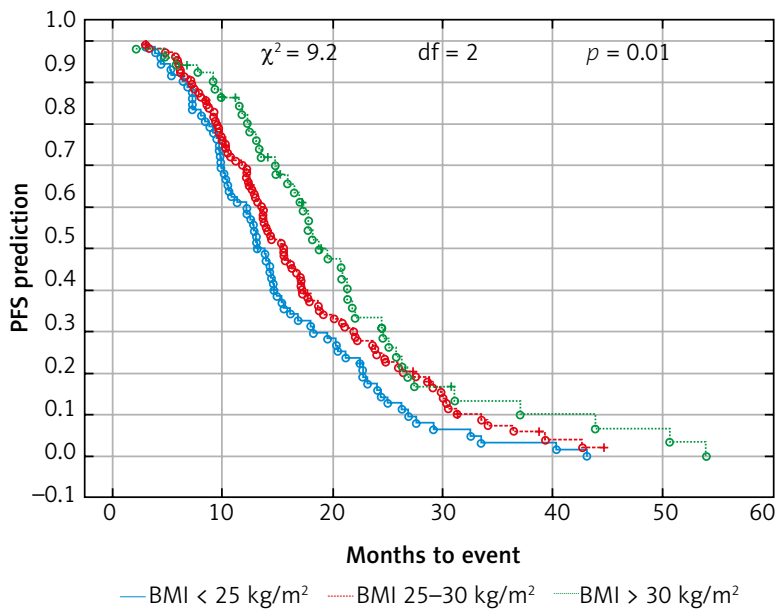

Fig. 2. Probability of Kaplan-Meier's overall survival (OS) curves in patients with body mass index (BMI): $<25 \mathrm{~kg} / \mathrm{m}^{2}, 25-30 \mathrm{~kg} / \mathrm{m}^{2}$ and $>30 \mathrm{~kg} / \mathrm{m}^{2}$ treated with bevacizumab plus chemotherapy 
Table 2. Efficacy and toxicity of bevacizumab plus chemotherapy in metastatic colorectal cancer patients according to BMI in univariate analysis

\begin{tabular}{|c|c|c|c|c|c|c|}
\hline \multirow{2}{*}{\multicolumn{2}{|c|}{ Parameter }} & BMI category & & & & \\
\hline & & $\begin{array}{c}<25 \mathrm{~kg} / \mathrm{m}^{2} \\
(n=74)\end{array}$ & $\begin{array}{l}25.0-29.9 \mathrm{~kg} / \mathrm{m}^{2} \\
(n=109)\end{array}$ & $\begin{array}{c}>30.0 \mathrm{~kg} / \mathrm{m}^{2} \\
(n=54)\end{array}$ & $\begin{array}{c}\text { Total } \\
(n=237)\end{array}$ & $p$-value \\
\hline \multicolumn{2}{|c|}{$\begin{array}{l}\text { Overall survival bevacizumab-FOLFOX therapy } \\
\text { (median, months) }\end{array}$} & 13.1 & 14.3 & 17.5 & 14.6 & \multirow[t]{4}{*}{0.01} \\
\hline \multicolumn{2}{|l|}{6 month OS } & $89 \%$ & $91 \%$ & $91 \%$ & $89 \%$ & \\
\hline \multicolumn{2}{|l|}{1 year OS } & $59 \%$ & $65 \%$ & $74 \%$ & $65 \%$ & \\
\hline \multicolumn{2}{|l|}{2 years OS } & $14 \%$ & $21 \%$ & $26 \%$ & $20 \%$ & \\
\hline \multicolumn{2}{|c|}{$\begin{array}{l}\text { Progression-free survival bevacizumab- } \\
\text { FOLFOX therapy (median, months) }\end{array}$} & 7.3 & 9.1 & 9.4 & 8.8 & 0.033 \\
\hline \multirow{3}{*}{$\begin{array}{l}\text { Response to bevacizumab-FOLFOX } \\
\text { therapy }\end{array}$} & $C R+P R$ & $22(34 \%)$ & $27(41 \%)$ & $16(25 \%)$ & 65 & \multirow[t]{3}{*}{0.921} \\
\hline & SD & $37(29 \%)$ & $59(47 \%)$ & $31(24 \%)$ & 127 & \\
\hline & PD & $9(35 \%)$ & $12(46 \%)$ & $5(19 \%)$ & 26 & \\
\hline \multirow[t]{2}{*}{ Any grade of toxicity } & YES & 51 & 78 & 38 & 167 & \multirow[t]{2}{*}{0.929} \\
\hline & NO & 23 & 31 & 16 & 70 & \\
\hline
\end{tabular}

BMI - body mass index, OS - overall survival, PFS - progression-free survival, FOLFOX - chemotherapy with oxaliplatin, 5-fluorouracil, leucovorin, CR - complete remission, $P R$ - partial remission, $S D$ - stable disease, $P D$ - progression disease

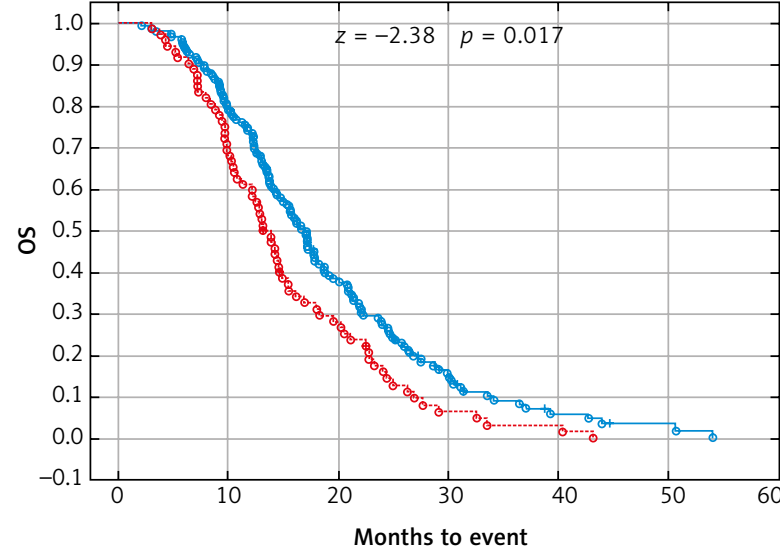

$-\mathrm{BMI}<25 \mathrm{~kg} / \mathrm{m}^{2} \quad \mathrm{BMI} \geq 25-30 \mathrm{~kg} / \mathrm{m}^{2}$

Fig. 3. Probability of Kaplan-Meier's overall survival (OS) curves in patients with body mass index (BMI): $<25 \mathrm{~kg} / \mathrm{m}^{2}$ and $\geq 25 \mathrm{~kg} / \mathrm{m}^{2}$ treated with bevacizumab plus chemotherapy

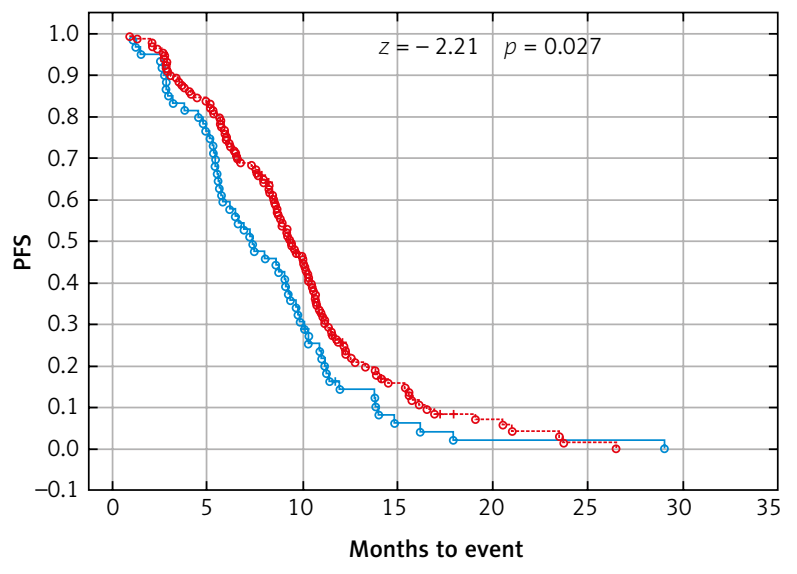

$-\mathrm{BMI}<25 \mathrm{~kg} / \mathrm{m}^{2} \quad \mathrm{BMI} \geq 25 \mathrm{~kg} / \mathrm{m}^{2}$

Fig. 5. Probability of Kaplan-Meier's progression free survival (PFS) curves in patients with body mass index (BMI): $<25 \mathrm{~kg} / \mathrm{m}^{2}$ and $\geq 25 \mathrm{~kg} / \mathrm{m}^{2}$ treated with bevacizumab plus chemotherapy

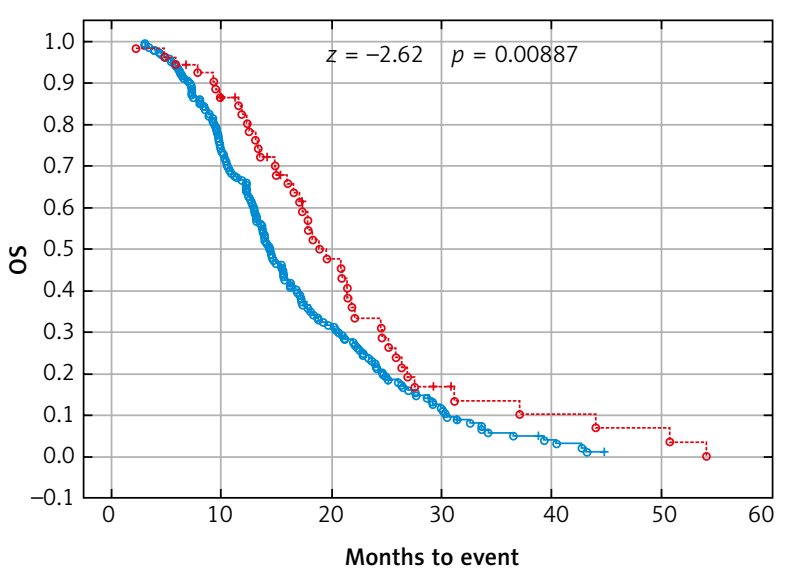

$-\mathrm{BMI}<30 \mathrm{~kg} / \mathrm{m}^{2} \quad \mathrm{BMI} \geq 30 \mathrm{~kg} / \mathrm{m}^{2}$

Fig. 4. Probability of Kaplan-Meier's overall survival (OS) curves in patients with body mass index (BMI): $<30 \mathrm{~kg} / \mathrm{m}^{2}$ and $\geq 30 \mathrm{~kg} / \mathrm{m}^{2}$ treated with bevacizumab plus chemotherapy

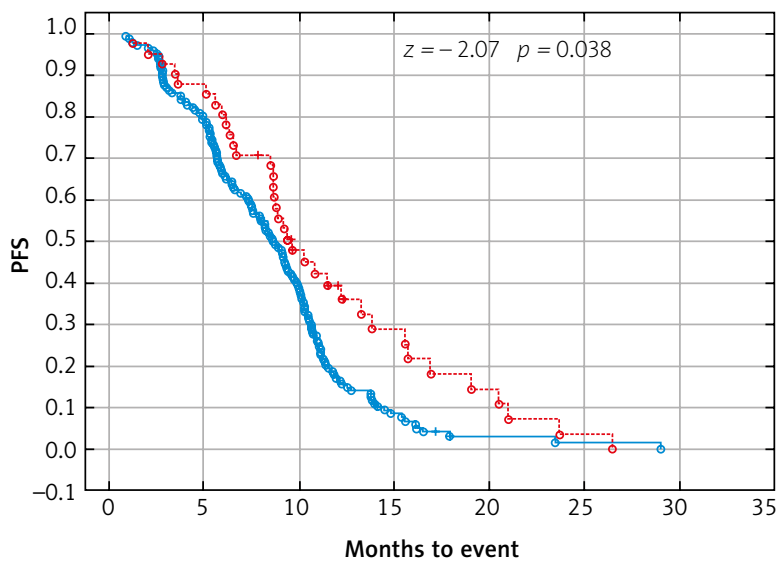

$-\mathrm{BMI}<30 \mathrm{~kg} / \mathrm{m}^{2} \quad \mathrm{BMI} \geq 30 \mathrm{~kg} / \mathrm{m}^{2}$

Fig. 6. Probability of Kaplan-Meier's progression free survival (PFS) curves in patients with body mass index (BMI): $<30 \mathrm{~kg} / \mathrm{m}^{2}$ and $\geq 30 \mathrm{~kg} / \mathrm{m}^{2}$ treated with bevacizumab plus chemotherapy 
Table 3. Median progression-free survival and overall survival according to body mass index categories

\begin{tabular}{lcrrr} 
BMI category & \multicolumn{2}{c}{ PFS (months) } & \multicolumn{2}{c}{ OS (months) } \\
& Median & $p$-value & Median & $p$-value \\
$<25 \mathrm{~kg} / \mathrm{m}^{2}$ & 7.3 & 0.075 & 13.1 & 0.061 \\
$\geq 25 \mathrm{~kg} / \mathrm{m}^{2}$ & 9.1 & & 15.6 & \\
$<30 \mathrm{~kg} / \mathrm{m}^{2}$ & 8.6 & 0.021 & 13.9 & 0.039 \\
$\geq 30 \mathrm{~kg} / \mathrm{m}^{2}$ & 9.4 & & 17.5 & \\
Total & 8.8 & 14.6 & &
\end{tabular}

BMI - body mass index, PFS - progression-free survival, OS - overall survival

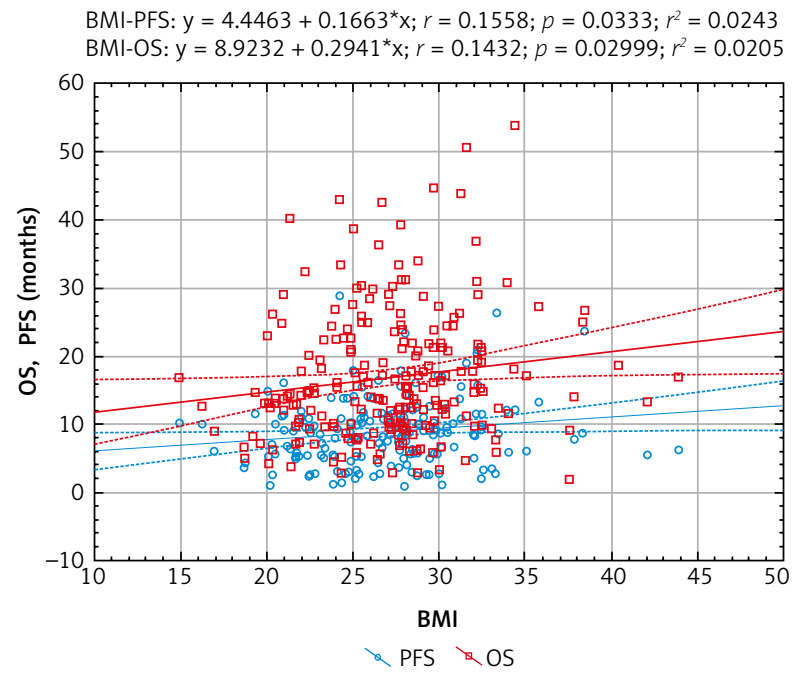

Fig. 7. Models of overall survival (OS) and progression-free survival (PFS) regression in metastatic colorectal cancer patients treated with bevacizumab plus chemotherapy depending on body mass in$\operatorname{dex}(\mathrm{BMI})$. Study of the significance of the correlation coefficient

or obstruction (G3: 2\% patients). There were no treatment-related deaths. Efficacy and toxicity results FOLFOX + bevacizumab according to BMI are shown in Table 2.

Due to previous studies, two, not three groups of patients with a specific BMI were also compared [14, 20].
Comparison of $\mathrm{BMI} \geq 25 \mathrm{~kg} / \mathrm{m}^{2}$ group vs. $\mathrm{BMI}<25 \mathrm{~kg} / \mathrm{m}^{2}$ group and $\mathrm{BMI} \geq 30 \mathrm{~kg} / \mathrm{m}^{2}$ group vs. $\mathrm{BMI}<30 \mathrm{~kg} / \mathrm{m}^{2}$ group revealed a significant improvement of median OS ( $p=0.017$ and $p=0.009$ respectively) (Figs. 3 and 4 ) and median PFS ( $p=0.027$ and $p=0.038$ respectively) (Figs. 5 and 6 ). Results of treatment in specific groups are presented in Table 3.

The regression analysis (Pearson's linear correlation coefficient) also confirmed that there is a statistically significant relationship between the length of OS and PFS and the BMI value. Higher BMI was associated with a better prognosis (Fig. 7).

The Cox hazard model show that the BMI class is an important risk factor. However, the Cox model also shows that the significance of the BMI class applies only to patients with $\mathrm{BMI}<25 \mathrm{~kg} / \mathrm{m}^{2}$. This rule applies to both OS and PFS. The Cox model is shown in Table 4.

Multivariate analysis confirmed the statistically significant prolongation of OS and PFS in the group with a BMI $\geq 30.0 \mathrm{~kg} / \mathrm{m}^{2} \mathrm{vs}$. BMI $<30.0 \mathrm{~kg} / \mathrm{m}^{2}$ and significant prolongation of PFS for patients in the group with a BMI of $\geq 25$ $-<30 \mathrm{~kg} / \mathrm{m}^{2}$ and a BMI $\geq 30.0 \mathrm{~kg} / \mathrm{m}^{2}(p=0.042)$ but not confirmed the improved OS ( $p=0.057)$. Multivariate analysis not confirmed statistically significant prolongation of $\mathrm{OS}$ and PFS in the group with a BMI $\geq 25.0 \mathrm{~kg} / \mathrm{m}^{2} \mathrm{vs}$. BMI $<25.0 \mathrm{~kg} / \mathrm{m}^{2}(p=0.061$ and 0,075 respectively).

Multivariate Cox proportional hazards models and multivariate analysis indicate that objective response (CR; complete response + PR; partial response) to bevacizumab with FOLFOX chemotherapy was associated with a statistically significant increase in OS and PFS. KRAS mutation was associated with worse prognosis in OS and PFS in Cox analysis and only in OS in multivariate analysis. The location of the primary lesion on the left side statistically prolonged OS in Cox and in multivariate analysis. Less than two metastatic sites and CEA within the normal range before the start of bevacizumab with FOLFOX chemotherapy statistically prolonged OS only in multivariate analysis (Table 5).

Table 4. Results of the multivariate Cox proportional hazards models

\begin{tabular}{|c|c|c|c|c|c|c|c|c|c|c|}
\hline \multirow[t]{2}{*}{ Parameter } & \multirow[t]{2}{*}{ Category } & \multirow[t]{2}{*}{$n$} & \multicolumn{4}{|c|}{ OS } & \multicolumn{4}{|c|}{ PFS } \\
\hline & & & HR & $95 \%$ & $\mathrm{Cl}$ & $p$-value & $H R$ & $95 \%$ & $\mathrm{Cl}$ & $p$-value \\
\hline Gender & Males vs. females & 130 & 0.85 & 0.59 & 1.22 & 0.375 & 1.02 & 0.73 & 1.42 & 0.906 \\
\hline \multirow[t]{2}{*}{ BMI } & $\begin{array}{l}<25 \mathrm{~kg} / \mathrm{m}^{2} \mathrm{vs} \\
\geq 30 \mathrm{~kg} / \mathrm{m}^{2}\end{array}$ & 74 & 1.83 & 1.12 & 2.99 & 0.015 & 1.79 & 1.13 & 2.84 & 0.047 \\
\hline & $\begin{array}{l}25.0-29.9 \mathrm{~kg} / \mathrm{m}^{2} \mathrm{vs} . \\
\geq 30 \mathrm{~kg} / \mathrm{m}^{2}\end{array}$ & 109 & 1.26 & 0.81 & 1.96 & 0.696 & 1.52 & 1.00 & 2.29 & 0.459 \\
\hline Age (years) & $\leq 65$ & 110 & 0.74 & 0.52 & 1.06 & 0.101 & 1.11 & 0.80 & 1.53 & 0.543 \\
\hline Side of primary tumor & Left vs. right & 185 & 0.58 & 0.39 & 0.86 & 0.007 & 0.69 & 0.47 & 1.03 & 0.071 \\
\hline Number of metastatic sides & 1 vs. $>1$ & 106 & 1.20 & 0.85 & 1.69 & 0.293 & 0.96 & 0.69 & 1.31 & 0.790 \\
\hline CEA & $\mathrm{N}$ vs. $>\mathrm{N} \mathrm{ng} / \mathrm{ml}$ & 30 & 1.20 & 0.76 & 1.89 & 0.431 & 0.91 & 0.57 & 1.45 & 0.677 \\
\hline \multirow{2}{*}{$\begin{array}{l}\text { Response to bevacizumab- } \\
\text { FOLFOX therapy after } 12 \text { weeks }\end{array}$} & $C R+P R$ vs. $P D$ & 66 & 0.19 & 0.11 & 0.33 & $<0.001$ & 0.59 & 0.39 & 0.89 & 0.012 \\
\hline & SD vs. PD & 127 & 2.07 & 1.36 & 3.15 & 0.565 & 1.69 & 1.12 & 2.55 & $<0.001$ \\
\hline KRAS gene status & Wild-type & 74 & 0.61 & 0.39 & 0.95 & $<0.001$ & 0.88 & 0.57 & 1.36 & 0.188 \\
\hline
\end{tabular}

$B M I$ - body mass index, OS - overall survival, PFS - progression-free survival, FOLFOX - chemotherapy with oxaliplatin, 5-fluorouracil, leucovorin, CR - complete remission, $P R$ - partial remission, $S D$ - stable disease, $P D$ - progression disease, $N$-in the normal range 
Due to the fact that all patients had performance status ECOG 0 or 1 (requirements of the national insurer), no comparisons were made for this factor.

\section{Discussion}

BMI is an index assessing body weight and informing about normal or abnormal body weight. Although new tools for assessing overweight and obesity are being studied: VFA, SFA, waist circumference.[9] BMI is still a basic and simpler tool for determining normal and abnormal body weight, for this reason BMI was used in our analysis.

The role of $\mathrm{BMI}$ as a predictor and prognostic factor in $m C R C$ is unclear and studied $[9,21]$. The prognostic effect of $\mathrm{BMI}$ is beginning to be well understood in the early stages of colon cancer, for which both underweight and obese patients have increased risk for progression or death [22, 23]. However, to date, the prognostic and predictive relationships between patients BMI and patient outcomes have been poorly understood in the metastatic setting [4]. It may affect the efficacy of bevacizumab in the treatment of obese patients with $\mathrm{mCRC}$. There are reports of lower efficacy of bevacizumab in obese patients $[14,20]$ and better effect of bevacizumab in patients with higher BMI [4, 24, 25].

In our study PFS was 8.8 months and the results in a similar study - the Eastern Cooperative Oncology Group Study E3200 study PFS was 7.3 months [26]. It should be concluded that our analysis concerned a very homoge- neous group of patients. All patients received bevacizumab with FOLFOX chemotherapy in the second line of mCRC treatment, and as first line treatment they received irinotecan based chemotherapy (XELIRI or FOLFIRI). In contrast, some studies the effect of BMI on the efficacy of bevacizumab related to the treatment of patients in the first or second line due to $\mathrm{mCRC}$ [23], or the use of bevacizumab chemotherapy with oxaliplatin, irinotecan or other drug [4, $14,20,24,25,27]$.

In the analysis of Artaç [14], patients are divided into two groups with $\geq 30.0 \mathrm{~kg} / \mathrm{m}^{2}$ and $<30 \mathrm{~kg} / \mathrm{mg}^{2}$ (i.e. obese and non-obese). The analysis of Artaç concerning treatment of $\mathrm{mCRC}$ patients with bevacizumab in the first line indicates lower efficacy of bevacizumab in the PFS range in obese patients, however, it does not show such a correlation for OS [14]. In this study, the prognosis was worse in patients with higher body weight only in specific subgroups; left-sided tumor location and the wild type K-RAS. Additionally, in this study, patients received different types of chemotherapy with bevacizumab, which could affect the results. We also do not know what treatment was used after disease progression and whether patients received anti-EGFR [14]. In the analysis of Aykan [20] patients are divided into two groups with $\mathrm{BMI} \geq 25 \mathrm{~kg} / \mathrm{m}^{2}$ and $<25 \mathrm{~kg} /$ $\mathrm{mg}^{2}$ (with increased and normal body weight). Similarly, in this analysis concerning $80 \mathrm{mCRC}$ patients treated with bevacizumab in the first line, patients with $\mathrm{BMI}<25$ had better PFS than patients with a weight $\geq 25 \mathrm{~kg} / \mathrm{m}^{2}$. This

Table 5. Multivariate analysis (analysis of the significance of predictors) in metastatic colorectal cancer patients treated with bevacizumab plus chemotherapy

\begin{tabular}{|c|c|c|c|c|c|}
\hline \multirow[t]{2}{*}{ Parameter } & & \multicolumn{2}{|c|}{ os } & \multicolumn{2}{|c|}{ PFS } \\
\hline & & $F$-value & $p$-value & $F$-value & $p$-value \\
\hline Age & $\begin{array}{l}\leq 65 \\
>65\end{array}$ & 0.97 & 0.325 & 0.07 & 0.788 \\
\hline Sex & $\begin{array}{l}\text { Male } \\
\text { Female }\end{array}$ & 0.30 & 0.586 & 0.13 & 0.718 \\
\hline BMI & $\begin{array}{c}<25 \mathrm{~kg} / \mathrm{m}^{2} \\
25.0-29.9 \mathrm{~kg} / \mathrm{m}^{2} \\
\geq 30.0 \mathrm{~kg} / \mathrm{m}^{2}\end{array}$ & 2.90 & 0.057 & 3.23 & 0.042 \\
\hline BMI & $\begin{array}{l}<25 \mathrm{~kg} / \mathrm{m}^{2} \\
\geq 25 \mathrm{~kg} / \mathrm{m}^{2}\end{array}$ & 3.53 & 0.061 & 3.20 & 0.075 \\
\hline BMI & $\begin{array}{c}<30 \mathrm{~kg} / \mathrm{m}^{2} \\
\geq 30.0 \mathrm{~kg} / \mathrm{m}^{2}\end{array}$ & 4.32 & 0.039 & 5.40 & 0.021 \\
\hline Number of metastatic sites & $\begin{array}{l}1 \\
>1\end{array}$ & 6.09 & 0.014 & 0.45 & 0.503 \\
\hline CEA & $\begin{array}{c}\text { in the normal range } \\
>\text { normal range }\end{array}$ & 4.00 & 0.047 & 0.27 & 0.604 \\
\hline $\begin{array}{l}\text { Response to bevacizumab-FOLFOX } \\
\text { therapy }\end{array}$ & $\begin{array}{l}C R+P R \\
S D \\
P D\end{array}$ & 17.07 & $<0.001$ & 22.16 & $<0.001$ \\
\hline Location & $\begin{array}{l}\text { Left site } \\
\text { Right site }\end{array}$ & 5.34 & 0.022 & 1.45 & 0.231 \\
\hline KRAS gene status & $\begin{array}{l}\text { Wild-type } \\
\text { Mutated } \\
\text { Not available }\end{array}$ & 37.66 & $<0.001$ & 5.98 & 0.003 \\
\hline
\end{tabular}

remission, $P R$ - partial remission, $S D$ - stable disease, $P D$ - progression disease 
study also used bevacizumab in the first or second line of treatment and different chemotherapy regimens which could affect the final results. In connection with analysis of Artaç and Aykan, we performed similar calculations in our group of patients and one of them confirmed the OS and PFS prolongation in the group of patients with $\mathrm{BMI}<$ $25 \mathrm{~kg} / \mathrm{m}^{2}$ or $<30 \mathrm{~kg} / \mathrm{m}^{2}$ analysis. It should be noted that the analyzed our group was very homogeneous, and all patients received the same kind of treatment, and imaging studies performed at 12 weeks. However, the division into two groups of patients seemed insufficient. In our analysis, three groups were identified, including patients with normal body mass $<25 \mathrm{~kg} / \mathrm{m}^{2}$, overweight $25-30$ and obese $>30 \mathrm{~kg} / \mathrm{m}^{2}$. Due to the small number of patients $(n=3)$ with $\mathrm{BMI}<18.5 \mathrm{~kg} / \mathrm{m}^{2}$, no separate group was assigned for patients with reduced body weight. This division seems more precise and better reflects the impact of weight on bevacizumab treatment. A similar classification was used in a pooled analysis of FFCD trials [24] which included data from 2085 patients enrolled in eight FFCD first-line mCRC trials from 1991 to 2013 was performed [24]. In this trial comparisons were made according to the BMI cut-off: obese (BMI > 30), overweight patients (BMI > $25-<30)$, normal BMI patients (BMI: 18.5-24) and thin patients $(\mathrm{BMI}<18.5)[24]$. This study confirmed that low BMI is a strong negative prognostic factor. No differences were found between obesity and treatment with bevacizumab, which were indicated by other studies. Similar conclusions were from the ARCAD analysis. This study collected data for 18,564 patients from $21 \mathrm{mCRC}$ first-line studies in 19972009. In the ARCAD analysis it was also shown that higher BMI statistically significantly improves PFS and OS in patients with mCRC [25]. In Zafar analysis [27], it was shown that patients with the lowest BMI had shorter median OS, suggesting that low BMI could be a poor-prognostic factor. Simkens in his analysis [28] from the CAIRO and CAIRO 2 study found that BMI is an independent prognostic factor for OS in $\mathrm{mCRC}$ receiving chemotherapy. However, this was not confirmed in patients receiving chemotherapy in combination with targeted therapy. In this study, patients received chemotherapy with bevacizumab and / or additional cetuximab as a first line treatment. In this group of patients, a non-significant trend was observed towards improvement of OS when the BMI was higher. This was not confirmed by the FFCD and ACARD analysis. FFCD and ACARD analysis did not show a negative impact on the survival of obese patients treated with bevacizumab in first line treatment $m C R C[24,25]$. Our analysis confirms these results in patients with $\mathrm{mCRC}$ receiving chemotherapy with bevacizumab as second-line treatment.

It should be noted that in our analyzes, the mutation in the KRAS gene was significantly associated with the overall survival of patients, but the data on the presence or absence of KRAS mutations were not available for $41 \%$ of patients. KRAS mutation is an unclear prognostic factor [29] and the effect of KRAS mutations on the survival of patients with $\mathrm{mCRC}$ treated with chemotherapy has not been confirmed in other studies [30-32]. However, there are studies indicating that KRAS wild-type may be associ- ated with better prognosis in patients with $\mathrm{mCRC}$ receiving capecitabine-based chemotherapy [33].

Our analysis has some limitations due to its retrospective nature, and missing data, but the value of our study is a very homogeneous group of patients and information that higher BMI was associated with statistically significantly better prognosis in patients with $\mathrm{mCRC}$ treated with chemotherapy with bevacizumab in second-line treatment was confirmed by several statistical analyzes. It is also one of the very few studies, which shows the relationship of $\mathrm{BMI}$ in the second line treatment of chemotherapy with bevacizumab.

\section{Conclusions}

Patients with $\mathrm{mCRC}$ treated with chemotherapy with bevacizumab in second-line treatment with higher BMI compared with normal weight patients have better prognosis in terms of PFS and OS. In this group, we found no evidence of changes in safety profile depending on BMI. Nevertheless, further large randomized studies are needed to assess the body weight on the effectiveness of chemotherapy in combination with bevacizumab.

The authors declare no conflict of interest.

\section{References}

1. Chan AT, Giovannucci EL. Primary prevention of colorectal cancer. Gastroenterology 2010; 138: 2029-2043.e10.

2. Flegal KM, Kit BK, Orpana H, Graubard BI. Association of all-cause mortality with overweight and obesity using standard body mass index categories: a systematic review and meta-analysis. JAMA 2013; 309: 71-82

3. Renehan AG, Tyson M, Egger M, Heller RF, Zwahlen M. Bodymass index and incidence of cancer: a systematic review and metaanalysis of prospective observational studies. Lancet 2008; 371: 569578

4. Kasi PM, Zafar SY, Grothey A. Is obesity an advantage in patients with colorectal cancer? Expert Rev Gastroenterol Hepatol 2015; 9: 1339-1342.

Miyazawa-Hoshimoto S, Takahashi K, Bujo H, Hashimoto N, Saito Y. Elevated serum vascular endothelial growth factor is associated with visceral fat accumulation in human obese subjects. Diabetologia 2003; 46: 1483-1488.

5. Silha JV, Krsek M, Sucharda P, Murphy LJ. Angiogenic factors are elevated in overweight and obese individuals. Int J Obes (Lond) 2005; 29: 1308-1314

6. Parekh N, Chandran U, Bandera EV. Obesity in cancer survival. Annu Rev Nutr 2012; 32: 311-342.

7. van Kruijsdijk RC, van der Wall E, Visseren FL. Obesity and cancer: the role of dysfunctional adipose tissue. Cancer Epidemiol Biomarkers Prev 2009; 18: 2569-2578.

8. Strulov Shachar S, Williams GR. The Obesity Paradox in Cancer-Moving Beyond BMI. Cancer Epidemiol Biomarkers Prev 2017; 26: 13-16.

9. Tobias DK, Pan A, Jackson CL, et al. Body-mass index and mortality among adults with incident type 2 diabetes. N Engl J Med 2014; 370: 233-244.

10. Andersen KK, Olsen TS. The obesity paradox in stroke: Lower mortality and lower risk of readmission for recurrent stroke in obese stroke patients. Int I Stroke 2015; 10: 99-104

11. Curtis JP, Selter JG, Wang Y, et al. The obesity paradox: body mass index and outcomes in patients with heart failure. Arch Intern Med 2005; 165: 55-61. 
12. Kazazi-Hyseni F, Beijnen JH, Schellens JH. Bevacizumab. Oncologist 2010; 15: 819-825.

13. Artac M, Korkmaz L, Coskun HS, et al. Bevacuzimab may be less effective in obese metastatic colorectal Cancer patients. J Gastrointest Cancer 2019; 50: 214-220.

14. Makey KL, Patterson SG, Robinson J, et al. Increased plasma levels of soluble vascular endothelial growth factor receptor 1 (sFlt-1) in women by moderate exercise and increased plasma levels of vascular endothelial growth factor in overweight/obese women. Eur J Cancer Prev 2013; 22: 83-89.

15. Karnofsky D, Burchenal J. The clinical evaluation of chemotherapeutic agents in cancer. In: Evaluation of Chemotherapeutic Agents, MacLeod C (ed.). Columbia University Press, New York, NY 1949: 191-205.

16. Zubrod C, Shneiderman M, Frei E, et al. Appraisal of methods for the study of chemotherapy in man: Comparative therapeutic trial of nitrogen mustard and thiophosphoramide. J Chron Dis 1960: 11: 7-33.

17. Jang GS, Kim MJ, Ha HI, et al. Comparison of RECIST version 1.0 and 1.1 in assessment of tumor response by computed tomography in advanced gastric cancer. Chin J Cancer Res 2013; 25: 689-694.

18. https://www.eortc.be/services/doc/ctc/ctcae_4.03_2010-06-14_ quickreference_5x7.pdf (access: 21 Sep 2019).

19. Aykan NF, Yildiz I, Sen F, et al. Effect of increased body mass index (BMI) on time to tumour progression (TTP) in unresectable meta static colorectal cancer (mCRC) patients treated with bevacizumab-based therapy. Med Oncol 2013; 30: 679.

20. Greenlee H, Unger JM, LeBlanc M, Ramsey S, Hershman DL. Association between Body Mass Index and Cancer Survival in a Pooled Analysis of 22 Clinical Trials. Cancer Epidemiol Biomarkers Prev 2017; 26: 21-29.

21. Dignam JJ, Polite BN, Yothers G, et al. Body mass index and outcomes in patients who receive adjuvant chemotherapy for colon cancer. J Natl Cancer Inst 2006; 98: 1647-1654.

22. Sinicrope FA, Foster NR, Yothers G, et al. Body mass index at diagnosis and survival among colon cancer patients enrolled in clinical trials of adjuvant chemotherapy. Cancer 2013; 119: 1528-1536.

23. Aparicio T, Ducreux M, Faroux R et al. Overweight is associated to a better prognosis in metastatic colorectal cancer: A pooled analysis of FFCD trials. Eur J Cancer 2018; 98: 1-9.

24. Renfro LA, Loupakis F, Adams RA et al. Body mass index (BMI) as prognostic in metastatic colorectal cancer (mCRC): A pooled analysis of 21 first-line trials in the ARCAD database. J Clin Oncol 2016; 34: 144-150.

25. Giantonio BJ, Catalano PJ, Meropol NJ et al. Bevacizumab in combination with oxaliplatin, fluorouracil, and leucovorin (FOLFOX4) for previously treated metastatic colorectal cancer: results from the Eastern Cooperative Oncology Group Study E3200. J Clin Oncol 2007: 25: 1539-1544.

26. Zafar Y, Hubbard J, Van Cutsem E, et al. Survival Outcomes According to Body Mass Index (BMI): Results from a Pooled Analysis of 5 Observational or Phase IV Studies of Bevacizumab in Metastatic Colorectal Cancer (mCRC). Barcelona: ESMO World Congress on Gastrointestinal Cancer; 2015 Abstract LBA-01.

27. Simkens LH, Koopman M, Mol L, et al. Influence of body mass index on outcome in advanced colorectal cancer patients receiv ing chemotherapy with or without targeted therapy. Eur J Cancer 2011; 47: 2560-2567.

28. Boussios S, Ozturk MA, Moschetta M, et al. The Developing Story of Predictive Biomarkers in Colorectal Cancer. J Pers Med 2019; 9: pii: E12.

29. Rui YY, Zhang D, Zhou ZG, Wang C, Yang L, Yu YY, Chen HN. Can K-ras gene mutation be utilized as prognostic biomarker for colorectal cancer patients receiving chemotherapy? A meta-analysis and systematic review. PLoS One 2013; 8: e77901.

30. Xie MZ, Li JL, Cai ZM, Li KZ, Hu BL. Impact of primary colorectal Cancer location on the KRAS status and its prognostic value. BMC Gastroenterol 2019; 19: 46.

31. Sun DC, Shi Y, Wang YR, et al. KRAS mutation and primary tumor location do not affect efficacy of bevacizumab-containing chemotherapy in stage IV colorectal cancer patients. Sci Rep 2017; 7: 14368.
32. Yarom N, Gresham G, Boame N, Jonker D. KRAS Status as a Predictor of Chemotherapy Activity in Patients With Metastatic Colorectal Cancer. Clin Colorectal Cancer 2019; 18: e309-e315.

\section{Address for correspondence}

\section{Bożena Cybulska-Stopa}

Clinical Oncology Clinic

Maria Sklodowska-Curie National Research Institute of Oncology

Cracow Branch

11 Garnacarska St.

31-115 Krakow, Poland

e-mail: bcybulskastopa@vp.pl

Submitted: 22.02 .2020

Accepted: 13.03.2020 